\title{
Childhood Variation in Skeletal and Dental Development
}

\author{
Anna L.M. Rautman ${ }^{1,2^{*}}$ and Heather J.H. Edgar ${ }^{1,2}$ \\ ${ }_{1}^{1}$ Department of Anthropology, University of New Mexico \\ ${ }^{2}$ Office of the Medical Investigator, University of New Mexico School of Medicine, Albu- \\ querque, New Mexico
}

Keywords: dental development, skeletal development, inter-individual variation

\begin{abstract}
The existing research comparing variation in developmental timing of skeletal and dental systems has focused on cross-sectional correlations of group means throughout late childhood. We used a longitudinal sample of 100 White American girls to compare developmental variation from 3-12 years to improve our understanding of developmental variation. The sample was divided into two sets (dental and skeletal) of three subgroups (delayed, average, or advanced) based on development at age three. Repeated measure ANOVA and Tukey's HSD analyses examined the longitudinal maturation of: 1) skeletal development of skeletal subgroups, 2) dental development of skeletal subgroups, 3) dental development of dental subgroups, and 4) skeletal development of dental subgroups.

The four models demonstrated significant differences between subgroup developmental trajectories. Pairwise comparisons of same-system development (analyses 1 and 3) found all comparisons to be significant; this was not the case for pairwise comparisons across systems (analyses 2 and 4). Only the advanced group was consistently different across all combinations.

Results suggest that the pace of development differs among delayed, average, and advanced individuals, and between dental and skeletal systems. Therefore, to fully explore the relationship between the systems, the full range of variation in the timing of development is required.
\end{abstract}

The skeletal and dental systems have long been subjects of study in humans. Existing studies of the two systems focus either on the sample mean expression or on the correlation between the two systems across the entire sample. This paper examines whether the variation between the systems' developmental trajectories varies between individuals who were delayed, average, or advanced in their development at an early age. Individuals within the average subgroup are included as a baseline with which to compare how the developmental trajectories of delayed and advanced individuals differ.

The general order and timing of how a juvenile develops into an adult is consistent among individuals. Here, development is used to refer to the change and refinement in shape of objects from their juvenile form to their completed adult appearance (Greulich \& Pyle, 1959; Moorrees, Fanning, \& Hunt, 1963). This is to differentiate development from growth, which refers to changes in size (Ogden et al., 2002; WHO Multicenter Growth Reference Study Group, 2006). The overall order of development, the order at which different bones and epiphyses form and fuse or teeth mineralize, is canalized. Canalization refers to the fact that de- velopmental reactions "adjust so as to bring about one definite end-result regardless of minor variations in conditions during the course of the reaction" (Waddington, 1942:563). The canalization of the skeletal and dental systems has long lent these systems to being used to estimate chronological age (Greulich \& Pyle, 1959; Moorrees, Fanning, \& Hunt, 1963; Tanner, 1978).

As the development of the skeletal and dental systems roughly correspond to chronological age, it follows that the two systems should be correlated. The correlation is not perfect due to variation between, and even within, individuals. Variation within and between individuals is inherent to canalization (Flatt, 2005; Waddington, 1942). A pletho-

*Correspondence to:

Anna L.M. Rautmann

Department of Anthropology

University of New Mexico

Albuquerque, New Mexico

arautman@unm.edu

This paper was the recipient of the Albert A. Dahlberg prize awarded by the Dental Anthropology Association in 2019. 
ra of environmental, genetic, and epigenetic factors contributes to the range of variation. Regardless of the cause or influence, the entire range of skeletal and dental developmental variation between people is the inter-individual variation in developmental timing (IVDT).

The environment can influence IVDT either as developmental stressors (nutritional or pathological) or via developmental plasticity. Developmental plasticity is the phenotypic response to the environment given an individual's genetic and epigenetic profile (Hochberg et al., 2011; Houston \& McNamara, 1992; Kuzawa, 2012; Wang et al., 2014). Genetic variation and developmental plastic variation are susceptible to evolutionary forces, referred to at the inter-species level as heterochrony (Bogin, 1997; Love, 2014). An example of genetic and epigenetic differences in IVDT include the known difference between the sexes (Badyaev, 2002; Ogden et al., 2002); males are known to develop more slowly on average than females (Badyaev, 2002; Greulich \& Pyle, 1959).

Differences in ancestry also must be considered when using developmental timing standards, as a method developed for one population may not be accurate for another population. This can result in either under or overestimation of an individual's developmental age (Haiter-Neto, Kurita, Menezes, \& Casanova, 2006; Zhang, Sayre, Vachon, Liu, \& Huang, 2009). Additionally, differences in population histories (e.g. famine or slavery) can delay or slow the development of disadvantaged groups (Jasienska, 2013; Ribot \& Roberts, 1996).

Non-evolutionary related variation over time also can occur. This is secular change, which is often associated with variation in environments such as improved nutrition and increased caloric intake (Garn, 1987). While the effects of secular change on the skeletal system and on total body size have been known for well over a century (Boas, 1912), the possibility of secular change affecting the dental system is a more recent field of study (Cardoso, Heuze, \& Julio, 2010; Nadler, 1998; Rautman \& Edgar, 2013). Regardless of the many causes, origins, and types, the entire range of variation is included in IVDT.

When the two systems are compared to each other, rather than to chronological age, a common finding is that the skeletal system is more susceptible to environmental and developmental stressors than is the dental (Cardoso, 2007b, 2007a; Demirjian, Buschang, Tanguay, \& Kingnorth Patterson, 1985; Flores-Mir, Mauicio, Orellena, \& Major, 2005; Lewis \& Garn, 1960). Large discrepancies between chronological age and either skeletal or dental age may be an indicator of an underlying disease or condition or of some other developmental stressor.

Numerous studies of the skeletal and dental systems have considered the systems individually and together (Cardoso, 2007b; Hunt \& Gleiser, 1955; Lauterstein, 1961; Lewis \& Garn, 1960). Existing studies comparing the development primarily focus on mean/median/modal developmental phenotype, or else the correlation across the entire sample. The mean (most commonly reported) phenotype is crucial to understanding the development of that phenotype. However, the mean expression is not informative about the range of possible variation. Such studies assume that the approach to development is the same across the range of IVDT, and that the mean expression is sufficient. By reporting or considering standard deviation in addition to the mean, more focus is placed on the range of variation (Al-Juboori, Saloom, \& Al-Bustani, 2012; Bagherpour, Pousti, \& Adelianfar, 2014; Gupta, Divyashree, Abhilash, Bijle, \& Murali, 2013; Sachan, Sharma, \& Tandon, 2011). Similarly, studies which utilize correlations do consider the entire range of variation (Anderson, Thompson, \& Popovich, 1975; Arora, 2009; Bagherpour et al., 2014; Lauterstein, 1961; Saglam \& Gazilerli, 2002). Such studies assume that the skeletal and dental correlation is the same across the entire range of IVDT. They ignore the possibility that the relationship between the systems may vary through the IVDT range.

The current research considers whether the relative relationship between the skeletal and dental systems is the same throughout the range of IVDT by comparing the correlation of skeletal and dental development between subgroups whose skeletal or dental development was delayed, average, or advanced early in life. Subgroups are here defined independently by either the completed skeletal or dental development at age three. The entire sample was divided into subgroups each with $20 \%$ of the total IVDT. Of the resulting five quantiles per system (five skeletal and five dental), only three per system were considered in the subsequent analysis. These three were those $20 \%$ who were delayed; those who were average, the middle $20 \%$; and those $20 \%$ who were advanced, all at age three. The delayed, average, and advanced skeletal quantiles were based on percentage of completed skeletal development at age three; while the delayed, average, and advanced dental quantiles were based on percentage of completed dental development at age three. The subsequent skeletal and 
dental development of each quantile were compared. The null hypothesis was that the relationship would be the same between the three skeletal quantiles and between the three dental quantiles. However, we predicted that the developmental trajectories would vary between those who were delayed, average, or advanced at age three. If the developmental trajectories were to vary between the three quantiles per system's IVDT, this would indicate that the relationship between the skeletal and dental systems is more complicated than is understood from the general assumption based on a consideration only of means or total sample correlations. This analysis of IVDT does not address the cause of the observed variation, nor should the findings be interpreted as being the result of a specific cause of variation.

\section{Materials and Methods}

The sample consists of 100 healthy females from the Bolton-Brush Growth Study, who were described by the study designers as White, of seemingly normal development, and who were without known major pathological conditions. Only one sex was considered for this study to avoid potential complication based on known sex differences in rates of development (Greulich \& Pyle, 1959; Stinson, 1985). In order to remove sex as a confounding variable females were chosen as they develop more quickly than males (Greulich \& Pyle, 1959; Humphrey, 1998).

The Bolton-Brush Growth Study is a combination of two related studies, the Brush Inquiry and Broadbent-Bolton Study, both of which began in the late 1920s in Cleveland, Ohio. The Brush Inquiry began in 1926 (Nelson, Hans, Broadbent Jr., \& Dean, 2000) (or 1928 (Behrents, 1984)) in order to study how healthy, normal children grew and developed (Nelson et al., 2000). Included among the data from this study are radiographs of the postcranial skeleton, information on the mental and physical health and growth of the child, and information about the child's family and home environment (Nelson et al., 2000). In 1929, the BroadbentBolton Study began with the initial purpose of understanding the dentofacial growth and development of normal, healthy children (Hans, Broadbent Jr., \& Nelson, 1994). This study included radiographs of the head and the hand-wrist, dental casts, and information on the health and developmental environment of each child. Although the two studies were independent, many participants were included in both studies. Of those individuals in the Brush Inquiry, $73 \%$ also participated in the
Broadbent-Bolton Study, while $67 \%$ of those in the Broadbent-Bolton Study were also in the Brush Inquiry (Hans et al., 1994; Nelson et al., 2000). Not all participants joined the studies at the same age. However, participants were seen every three months when less than one-year-old, every six months from one to five years old, and once a year after age five.

The selection criteria for the present study were that each girl must have been seen within three months of her third, sixth, ninth, and $12^{\text {th }}$ birthday. In cases in which pairs of sisters were seen at all four ages, only one sister was included. Birth dates ranged from January 1928 to May 1934 and were distributed as evenly as possible during this window. For each visit, the lateral cranial and handwrist radiographs were used to measure skeletal and dental development.

\section{Skeletal and Dental Development}

The level of skeletal development was determined by visual observation of left hand-wrist radiographs. The stage of development of 15 bones at 11 sites was determined using Greulich and Pyle's atlas of hand and wrist development (Greulich \& Pyle, 1959) to quantify the development of carpals, metacarpals, the radius, and ulna (Table 1). When a bone (e.g. trapezium) or epiphysis (e.g. first metacarpal) had not yet begun ossification, it was scored "1" (Greulich \& Pyle, 1959). When assignment to Greulich and Pyle's Stage 1 stated that ossification had already begun (e.g. scaphoid: "Stage 1: ossification usually begins from a single center, pg. 201), radiographs that showed no sign of ossification were scored as zero. Radiographs that were too blurry or out of focus to determine the devel-

Table 1. Skeletal development sites (Greulich and Pyle, 1959) with the range of ordinal stages and the total number of stages used to calculate obtained level of development. Stage "0" was added and defined as prior to the beginning of ossification.

\begin{tabular}{lcc}
\hline Development Site & $\begin{array}{c}\text { Range of } \\
\text { Stages }\end{array}$ & $\begin{array}{c}\text { Number } \\
\text { of Stages }\end{array}$ \\
\hline Proximal 1st phalanx & 1 to 10 & 10 \\
Distal 2nd $4^{\text {th }}$ metacarpals & 1 to 9 & 9 \\
Distal 5th metacarpal & 1 to 9 & 9 \\
Trapezium \& $1^{\text {st }}$ metacarpal & 1 to 12 & 12 \\
Trapezoid \& $2^{\text {nd }}$ metacarpal & 1 to 10 & 10 \\
Capitate \& Hamate & 0 to 10 & 11 \\
Scaphoid & 0 to 8 & 9 \\
Lunate & 0 to 8 & 9 \\
Triquetral \& Pisiform & 0 to 8 & 9 \\
Radius & 1 to 11 & 11 \\
Ulna & 1 to 11 & 11 \\
\hline
\end{tabular}


opment at a site were scored as "non-observable" and excluded from further analysis.

One author (ALMR) determined the level of attained dental development by visual examination of the permanent dentition as observed from lateral radiographs. The presence or absence of each tooth was noted, as was the stage of development. Stages were determined using Moorrees et al. (1963) stages from AlQahtani et al.'s (2010) dental age estimation chart (Table 2). Due to the nature of lateral radiographs, differentiating the central versus lateral incisor was complicated and was solved by scoring only one, presumably the first central incisor in both the maxilla and mandible. Although orthopantomograms are better suited for observing individual tooth development, the Moorrees et al. (1963) method was developed based on lateral radiographs. Furthermore, orthopantomograms are a more recent technological image and not commonly available in longitudinal studies such as the Bolton-Brush Growth Study. Additional teeth scored included maxillary and mandibular canines, third and fourth premolars, as well as first, second, and third molars. Siding was not possible, but only one tooth at each position was scored. When the quality of the radiograph or the angle prevented positively identifying a specif- ic tooth, the tooth was scored as "non-observable."

\section{Intra-Observer Error}

To test for consistent scoring, a subset of $20 \%$ of the radiographs were randomly selected to form an intra-observer data subset. This subset of 78 handwrist radiographs and 80 lateral cephalograms were then scored a second time. The numeric and "non-observable" scores per hand-wrist location and tooth were included. All scores within the intra-observer subset were compared between rounds of observations using a weighted Cohen's Kappa test (Viera \& Garrett, 2005) using the statistical package $\mathrm{R} \times 64$ 3.2.3. Data from repeat observations were used only for the intra-observer test and were not included in further analyses.

\section{Developmental Level Scoring}

At each age, a composite score of percentage of attained skeletal and dental development was calculated for each individual. Hand-wrist radiographs with fewer than seven scored sites were excluded from analysis. Skeletal ordinal stages were converted into numbered levels (see Table 1). Ratios per site of percent development obtained were calculated based on the sites' number of stages and then a composite score of average skeletal

Table 2. Dental development stages (Moorrees et al., 1963; AlQahtani et al., 2010) and their description. The number in the Stage column is the number used to calculate level of obtained development.

\begin{tabular}{|c|c|c|c|}
\hline Stage & Description & Stage & Description \\
\hline A-NP & $\begin{array}{l}\text { Tooth absent, formation not yet begun. Com- } \\
\text { parison between ages was used to distinguish } \\
\text { from congenitally absent teeth. }\end{array}$ & $\begin{array}{l}\text { Crc } \\
6\end{array}$ & Crown complete with defined pulp roof \\
\hline $\mathrm{Ci}$ & Initial cusp formation & $\mathrm{Ri}$ & Initial root formation \\
\hline 1 & - nn & 7 & 同 \\
\hline Cco & Coalescence of cusps & $\mathrm{R}^{1 / 4}$ & $\begin{array}{l}\text { Root length less than crown length. Poste- } \\
\text { rior teeth have visible bifurcation area. }\end{array}$ \\
\hline 2 & - m & 8 & 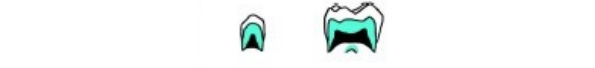 \\
\hline Coc & Cusp outline complete & $\mathrm{R} 1 / 2$ & Root length equals crown length \\
\hline 3 & $0 \infty$ & 9 & ก \\
\hline $\operatorname{Cr} 1 / 2$ & Crown half complete with dentine formation & $\mathrm{R} 3 / 4$ & $\begin{array}{l}\text { Three quarters of root length developed } \\
\text { with diverge ends }\end{array}$ \\
\hline 4 & $\Delta$ & 10 & थ \\
\hline $\mathrm{Cr} 3 / 4$ & Crown three quarters complete & Rc+ & $\begin{array}{l}\text { Root length complete. } \\
\text { With parallel ends or closed apex. }\end{array}$ \\
\hline 5 & $\approx$ & 12 & 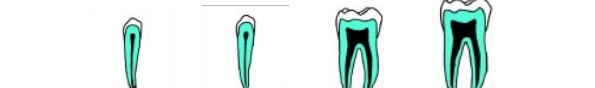 \\
\hline
\end{tabular}


development was calculated. Similarly, lateral radiographs with fewer than eight scored teeth were excluded from analysis. The ordinal stages of dental development were converted into numbered levels (see Table 2), ranging from zero for teeth whose formation had yet to begin, to 12 for completely formed teeth. Numeric levels were then converted to percentages of completed development and a composite score of average dental development was calculated. The final sample sizes of usable radiographs per age varied from 92 to 97 for skeletal development and 90 to 97 for dental development (Table 3a).

Determining Quantile Subgroups: Delayed, Average, and Advanced

Quantiles used for analysis included individuals who were delayed, average, or advanced in their skeletal or dental development at age three, representing the range of normal variation. To define these quantiles, we divided the entire sample into two matched sets of five subgroups. Each set of quantiles was defined either by the percentage of completed skeletal development (skeletal quantiles) or the percentage of completed dental development (dental quantiles) at age three. When defining each set of quantiles, the systems were considered independently. Therefore, an individual's ranking of skeletal development influenced only their classification in the skeletal quantiles and did not influence the placement in the dental quantiles, and vice versa. The delayed quantile includes those individuals who had achieved the least amount of development, those in the lowest $20^{\text {th }}$ percentile. The average quantile included individuals in the middle quantile, those whose development was between the $40^{\text {th }}$ and $60^{\text {th }}$ percentiles. The advanced quantile contained the most developmentally advanced individuals, those in the highest $20^{\text {th }}$ percentile.

Subsequent analyses comparing developmental trajectories were based on two sets of three quantiles: delayed, average, and advanced skeletal development quantiles; and delayed, average, and advanced dental quantiles. All six quantiles were of similar size (Table $3 b)$. Although quantiles were defined based on one system at a time, some individuals fell in quantiles of interest for both systems (Table 3c). By using these six quantiles, four questions could be examined:

For quantiles based on skeletal development: 1) How do the skeletal developmental trajectories compare between skeletal quantiles?
Table 3. Sample sizes after percent of obtained development was calculated. (a) Total sample size of usable radiographs prior to quantile assignment. (b) Sample size per skeletal and dental quantiles of interest. (c) Sample size of individuals who were in the quantiles of interest in both systems.

\begin{tabular}{cccc}
\hline \multicolumn{4}{c}{ (a) Sample pre-quantiles assigned } \\
\hline Age & Dental & Skeletal & Both \\
3 & 90 & 92 & 84 \\
6 & 93 & 97 & 90 \\
9 & 97 & 97 & 95 \\
12 & 97 & 95 & 92 \\
all ages & 83 & 84 & 72 \\
\hline
\end{tabular}

(b) Per quantile of interest by system

\begin{tabular}{lccc} 
& Delayed & Mean & Advanced \\
\cline { 2 - 4 } $\begin{array}{l}\text { Skeletal development } \\
\text { based quantiles } \\
\text { (skeletal quantiles) }\end{array}$ & 18 & 18 & 18 \\
$\begin{array}{l}\text { Dental development } \\
\text { based quantiles } \\
\text { (dental quantiles) }\end{array}$ & 19 & 18 & 19 \\
\hline
\end{tabular}

\begin{tabular}{|c|c|c|c|c|}
\hline \multirow{2}{*}{\multicolumn{2}{|c|}{ (c) Per quantiles of in }} & \multicolumn{3}{|c|}{$\begin{array}{l}\text { rest for both systems } \\
\text { Skeletal quantiles }\end{array}$} \\
\hline & & Delayed & Mean & Advanced \\
\hline \multirow{3}{*}{$\begin{array}{l}\text { Dental } \\
\text { quan- } \\
\text { tiles }\end{array}$} & Advanced & 3 & 6 & 4 \\
\hline & Mean & 3 & 1 & 4 \\
\hline & Delayed & 5 & 1 & 5 \\
\hline
\end{tabular}

2) How do the dental developmental trajectories compare between skeletal quantiles?

For quantiles based on dental development: 1) How do the dental developmental trajectories compare between dental quantiles?

2) How do the skeletal developmental trajectories compare between dental quantiles?

\section{Statistical Analysis}

Descriptive statistics were calculated for the total original sample and for each quantile of interest at all four ages. Additionally, attained development composite scores were plotted against exact chronological age. For each plot, logistic growth curves (Fox \& Weisberg, 2010) were calculated and added to the plots. Repeated measure ANOVA was used to test the significance of statistical models based on each question. These statistical models incorporated the composite score of obtained development 
for a given system (Development) as the dependent variable and individual (Pt.ID), chronological age (Age), baseline quantile group (Q.subgroup), and the interaction of age and baseline quantile group as the independent variables, with repeated measures by individual (Pt. ID).

$$
\text { Development } \sim \text { Pt.ID +Age+ Q.subgroup }
$$

Model 1 corresponds with the first question: How do the skeletal developmental trajectories compare between skeletal quantiles? Therefore, in Model 1 the dependent developmental variable is skeletal development, and the Q.subgroup are the three skeletal baseline quantile groups. Model 2 corresponds to the second question and uses dental development for the dependent variable, and uses the same three skeletal baseline quantile groups for the Q.subgroup. This pattern continues through the remaining two questions.

When the repeated measure ANOVA showed the statistical model to be significant, a Tukey's HSD (honest significant difference) test was run for pairwise comparison of quantile groups. Analyses were completed using $\mathrm{R} \times 64$ 3.2.3 and STATA/IC 11.2 statistical programs.

\section{Results}

Weighted Cohen's Kappa test (Viera \& Garrett, 2005) of intra-observer error showed consistent agreement in development scores. For dental development, the weighted Cohen's Kappa was 0.811, demonstrating almost perfect agreement, while the weighted Cohen's Kappa for skeletal development was 0.792 , demonstrating substantial agreement and falling just below the 0.81 cutoff for almost perfect agreement (Landis \& Koch, 1977).

In agreement with previous studies (Cardoso, 2007b; Flores-Mir et al., 2005; Lewis \& Garn, 1960), descriptive statistics show that, overall (Table 4a), skeletal development is more variable than dental development at all ages (Table 5a). However, this difference did not hold up for all quantiles of interest, as for some quantiles, the variation in dental development was greater than for skeletal.

Results for Quantiles Based on Skeletal Development For skeletal based quantiles, the descriptive statistics (Table $4 \mathrm{~b}$ ) fail to demonstrate consistently greater skeletal development variation than dental (Table 5b). At age three, the reverse is true for all three quantiles. The dental development continues to be more variable at age six for the average and advanced quantiles. At age nine, the dental varia- tion is greater only for the advanced quantile, but at age 12 , only the average quantile demonstrates higher dental variation than skeletal. These differences suggest that there are differences in skeletal and dental development between those who were delayed, average, or advanced in their skeletal development at age three.

Model 1: Skeletal Developmental Trajectories of Skeletal Quantiles

Figure 1a depicts skeletal developmental trajectories of the three skeletal quantiles versus exact chronological age. The three lines represent the logistic growth curves per skeletal quantile. The difference in mean age per quantile decreases continuously between the delayed and advanced quantiles as the individuals age. Despite the narrowing differences, the three quantiles continue to follow their own trajectories. A repeated measure ANOVA was run on Model 1, comparing the skeletal developmental trajectories of the three skeletal quantiles (Table 6a). The model was found to be significant $(\mathrm{F}=179.43 ; \mathrm{p}<0.0001)$. Age, as well as the interaction of age and skeletal quantile, was also significant. The R-squared value for the model was 0.9869 . Based on the model's significance, a Tukey's HSD pairwise comparison was run to test the effect each quantile's pairing had on the complete model (Table 6b). This test demonstrated that all three comparisons between the skeletal quantiles were significantly different in their mean scores.

\section{Model 2: Dental Developmental Trajectories of Skeletal Quantiles}

Figure $1 \mathrm{a}$ and $1 \mathrm{~b}$ depict the developmental trajectories versus exact chronological age of the same individuals within the skeletal quantiles of interest. However, while Figure 1a compares the skeletal development, Figure $1 \mathrm{~b}$ compares the dental development. The trajectories of the delayed and average quantiles are similar and, in fact, cross over each other. A repeated measure ANOVA was run on Model Q2, comparing the dental development of the three skeletal quantiles (Table 7a). The model was significant $(\mathrm{F}=128.47 ; \mathrm{p}<0.0001)$. The influence of age was significant in Model 2, as it was in Model 1. However, unlike Model 1, the interaction between age and the skeletal quantiles was not significant $(\mathrm{p}=0.4578)$. The R-squared was 0.9822 , which is slightly lower than that for Model 1 yet still a high value. Because the model was significant, a Tukey's HSD pairwise comparison was run (Table $7 \mathrm{~b})$. The results of this test differ from those of Model 1 in that not all the pairwise comparisons 
Table 4. Descriptive statistics of the skeletal and dental development for the entire sample, (b) three skeletal quantiles of interest, and (c) the three dental quantiles of interest.

\begin{tabular}{lcccc}
\hline \multicolumn{4}{c}{ (a) Total sample's development } \\
\hline & \multicolumn{2}{c}{ Skeletal } & \multicolumn{2}{c}{ Dental } \\
& mean & SD & mean & SD \\
\hline age 3 & 0.3226 & 0.0630 & 0.2762 & 0.0364 \\
age 6 & 0.5372 & 0.0628 & 0.5199 & 0.0561 \\
age 9 & 0.7083 & 0.0658 & 0.7326 & 0.0503 \\
age 12 & 0.8906 & 0.0483 & 0.9107 & 0.0405 \\
\hline
\end{tabular}

\begin{tabular}{|c|c|c|c|c|c|c|c|c|}
\hline \multirow{13}{*}{ 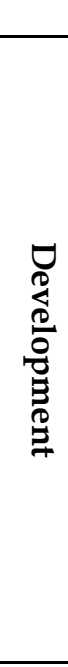 } & \multicolumn{8}{|c|}{ (b) Skeletal based Quantiles } \\
\hline & \multirow{6}{*}{ 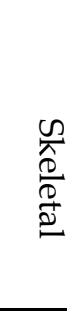 } & & \multicolumn{2}{|c|}{ Delayed-Skeletal } & \multicolumn{2}{|c|}{ Average-Skeletal } & \multicolumn{2}{|c|}{ Advanced-Skeletal } \\
\hline & & \multirow{5}{*}{$\begin{array}{l}\text { age } 3 \\
\text { age } 6 \\
\text { age } 9 \\
\text { age } 12\end{array}$} & \multirow{5}{*}{$\begin{array}{c}\text { mean } \\
0.2424 \\
0.4654 \\
0.6585 \\
0.8890\end{array}$} & \multirow{2}{*}{$\frac{\text { SD }}{0.0250}$} & \multirow{2}{*}{$\frac{\text { mean }}{0.3146}$} & \multirow{2}{*}{$\frac{\text { SD }}{0.0058}$} & \multirow{2}{*}{$\frac{\text { mean }}{0.4170}$} & \multirow{2}{*}{$\frac{\text { SD }}{0.0401}$} \\
\hline & & & & & & & & \\
\hline & & & & 0.0532 & 0.5521 & 0.0458 & 0.6059 & 0.0337 \\
\hline & & & & 0.0522 & 0.7174 & 0.0554 & 0.7815 & 0.0499 \\
\hline & & & & 0.0512 & 0.8976 & 0.0377 & 0.9081 & 0.0460 \\
\hline & \multirow{6}{*}{ 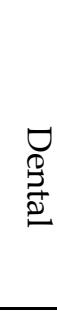 } & & \multicolumn{2}{|c|}{ Delayed-Skeletal } & \multicolumn{2}{|c|}{ Average-Skeletal } & \multicolumn{2}{|c|}{ Advanced-Skeletal } \\
\hline & & \multirow{5}{*}{$\begin{array}{l}\text { age } 3 \\
\text { age } 6 \\
\text { age } 9 \\
\text { age } 12\end{array}$} & \multirow{5}{*}{$\begin{array}{c}\text { mean } \\
0.2758 \\
0.4987 \\
0.7265 \\
0.9022 \\
\end{array}$} & \multirow{5}{*}{$\begin{array}{c}\text { SD } \\
0.0303 \\
0.0498 \\
0.0503 \\
0.0324 \\
\end{array}$} & \multirow{5}{*}{$\begin{array}{c}\text { mean } \\
0.2613 \\
0.5154 \\
0.7145 \\
0.8995\end{array}$} & \multirow{5}{*}{$\begin{array}{c}\text { SD } \\
0.0320 \\
0.0601 \\
0.0443 \\
0.0625 \\
\end{array}$} & \multirow{5}{*}{$\begin{array}{c}\text { mean } \\
0.2819 \\
0.5486 \\
0.7527 \\
0.9281 \\
\end{array}$} & SD \\
\hline & & & & & & & & 0.0410 \\
\hline & & & & & & & & 0.0639 \\
\hline & & & & & & & & 0.0632 \\
\hline & & & & & & & & 0.0355 \\
\hline \multirow{13}{*}{ 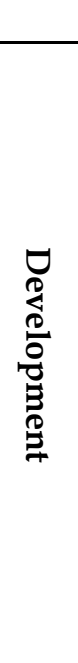 } & \multicolumn{4}{|c|}{ (c) Dental based Quantiles } & & & & \\
\hline & \multirow{6}{*}{ 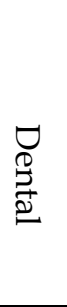 } & & \multicolumn{2}{|c|}{ Delayed-Dental } & \multicolumn{2}{|c|}{ Average-Dental } & \multicolumn{2}{|c|}{ Advanced-Dental } \\
\hline & & & mean & SD & mean & SD & mean & $\mathrm{SD}$ \\
\hline & & age 3 & 0.2256 & 0.0182 & 0.2783 & 0.0053 & 0.3265 & 0.0219 \\
\hline & & age 6 & 0.4974 & 0.0270 & 0.5230 & 0.0568 & 0.5298 & 0.0648 \\
\hline & & age 9 & 0.7033 & 0.0424 & 0.7358 & 0.0525 & 0.7647 & 0.0517 \\
\hline & & age 12 & 0.9026 & 0.0529 & 0.9160 & 0.0362 & 0.9199 & 0.0469 \\
\hline & & & Delay & ental & Avera & ental & Adv & Dental \\
\hline & & & mean & SD & mean & SD & mean & SD \\
\hline & $\frac{n}{\pi}$ & age 3 & 0.3153 & 0.0607 & 0.3181 & 0.0592 & 0.3274 & 0.0852 \\
\hline & $\frac{0}{0}$ & age 6 & 0.5348 & 0.0820 & 0.5237 & 0.0603 & 0.5335 & 0.0616 \\
\hline & 2 & age 9 & 0.7100 & 0.0814 & 0.7006 & 0.0720 & 0.7135 & 0.0706 \\
\hline & & age 12 & 0.8716 & 0.0613 & 0.8912 & 0.0409 & 0.9128 & 0.0300 \\
\hline
\end{tabular}


Table 5. Calculated difference of the variation (as measured by standard deviation) between skeletal and dental development.

\begin{tabular}{cc}
\hline a) SD: TS - TS \\
\hline \multicolumn{2}{c}{ Total sample: } \\
skeletal develop. - dental develop. \\
\hline Age 3 & 0.0266 \\
Age 6 & 0.0066 \\
Age 9 & 0.0155 \\
Age 12 & 0.0078 \\
\hline \hline
\end{tabular}

(b) SD: Q2 - Q3

Skeletal quantiles:

skeletal develop. - dental develop.

\begin{tabular}{llll}
\hline & Delayed & Average & Advanced \\
Age 3 & -0.0053 & -0.0261 & -0.0009 \\
Age 6 & 0.0034 & -0.0144 & -0.0303 \\
Age 9 & 0.0018 & 0.0111 & -0.0132 \\
Age 12 & 0.0188 & -0.0247 & 0.0104 \\
\hline
\end{tabular}

(c) SD: Q4 - Q1

Dental quantiles:

skeletal develop. - dental develop.

\begin{tabular}{llll}
\hline & Delayed & Average & Advanced \\
Age 3 & 0.0426 & 0.0539 & 0.0632 \\
Age 6 & 0.0549 & 0.0035 & -0.0032 \\
Age 9 & 0.0390 & 0.0196 & 0.0189 \\
Age 12 & 0.0084 & 0.0048 & -0.0169 \\
\hline
\end{tabular}

(a) Model 1: skeletal development of skeletal quantiles

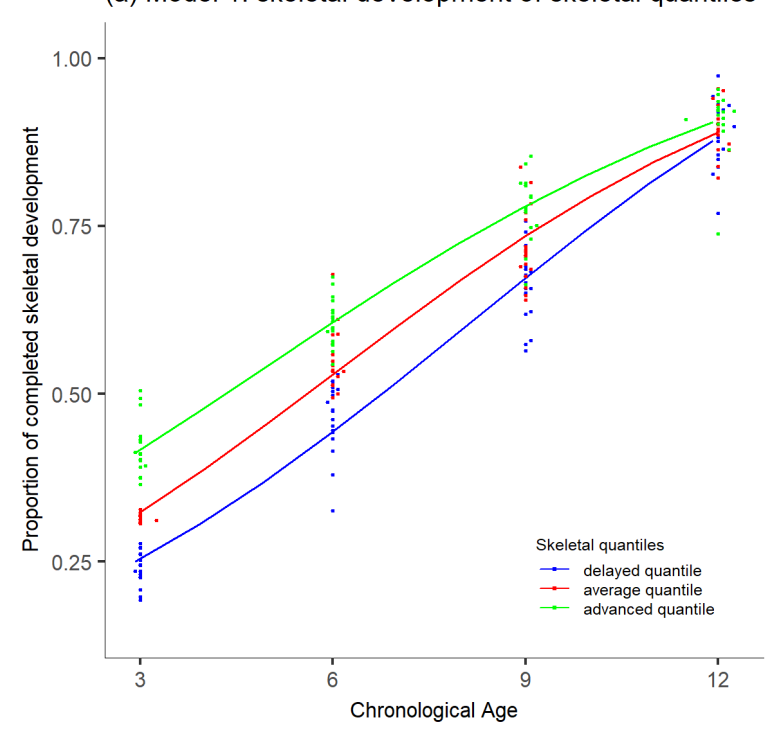

Table 6. Model 1: Skeletal development between skeletal quantiles. Pt.ID: individual; Age: patient's chronological age; Skeletal.Q: patient's skeletal quantile.

\begin{tabular}{|c|c|c|c|c|c|}
\hline \multicolumn{6}{|c|}{ (a) Repeat Measure ANOVA } \\
\hline \multicolumn{3}{|c|}{ Number of observations $=218$} & \multicolumn{2}{|c|}{ R-squared = } & 0.9869 \\
\hline \multirow[b]{2}{*}{ Source } & \multirow{2}{*}{$\begin{array}{c}\text { Root MSE = } \\
\text { Partial SS }\end{array}$} & \multirow{2}{*}{$\begin{array}{c}0.0305 \\
\mathrm{df}\end{array}$} & \multicolumn{2}{|c|}{ Adj R-squared = } & 0.9814 \\
\hline & & & MS & $\mathrm{F}$ & Prob $>$ F \\
\hline Model & 10.7138 & 64 & 0.1674 & 179.43 & 0 \\
\hline Pt.ID & 0.5387 & 55 & 0.0098 & 10.5 & 0 \\
\hline Age & 9.7514 & 3 & 3.2505 & 3483.98 & 0 \\
\hline Skeletal.Q & 0 & 0 & & & \\
\hline $\begin{array}{l}\text { Age \# Skel- } \\
\text { etal.Q }\end{array}$ & 0.1280 & 6 & 0.0213 & 22.87 & 0 \\
\hline Residual & 0.1427 & 153 & 0.0009 & & \\
\hline Total & 10.8565 & 217 & 0.0500 & & \\
\hline \multicolumn{6}{|c|}{ Between-subjects error } \\
\hline & Levels: & \multicolumn{4}{|c|}{$12(6 \mathrm{df})$} \\
\hline Lowest & s.e. variable: & \multicolumn{4}{|l|}{ Age } \\
\hline Covarian & pooled over: & \multicolumn{4}{|c|}{ Skeletal.Q (for repeated variable) } \\
\hline Rep & ted variable: & \multicolumn{4}{|c|}{ Pt.ID } \\
\hline
\end{tabular}

\section{(b) Tukey's HSD}

studentized range critical value $(.05,3,153)=3.3472$ uses harmonic mean sample size $=72.608$

\begin{tabular}{lcccc}
\hline quantile vs quantile & \multicolumn{2}{c}{ quantile means } & mean dif & HSD-test \\
delayed vs average & 0.5563 & 0.6174 & 0.0612 & $17.0724^{*}$ \\
delayed vs advanced & 0.5563 & 0.6767 & 0.1205 & $33.6101^{*}$ \\
average vs advanced & 0.6174 & 0.6767 & 0.0593 & $16.5377^{*}$ \\
\hline
\end{tabular}

(b) Model 2: dental development of skeletal quantiles

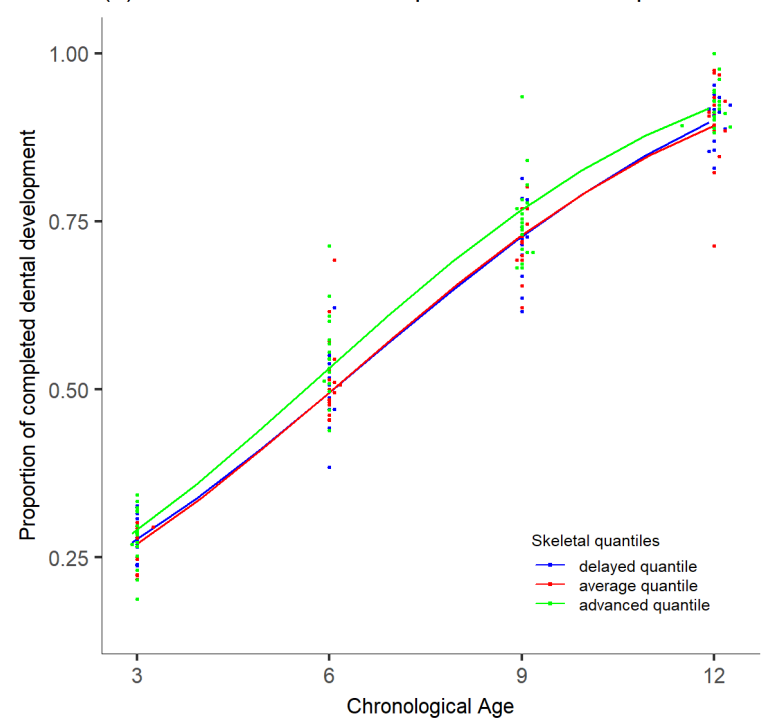

Figure 1. Logistic growth curves of skeletal quantiles: chronological age versus development. Plots of chronological age by proportion of completed skeletal (a) or dental (b) development based on skeletal development at age three, the delayed, average, and advanced skeletal quantiles. Logistic growth curves depict the developmental trajectories taken by those within each quantile. 
are significant. Only those comparisons that include the advanced quantile are significant, while the interaction between the delayed and average quantiles is not.

Table 7. Model 2: Dental development between skeletal quantiles. Pt.ID: individual; Age: patient's chronological age; Skeletal.Q: patient's skeletal quantile.

\section{(a) Repeat Measure ANOVA}

\begin{tabular}{|c|c|c|c|c|c|}
\hline \multirow{2}{*}{\multicolumn{3}{|c|}{$\begin{array}{l}\text { Number of observations }=214 \\
\text { Root MSE }=0.0388\end{array}$}} & \multicolumn{3}{|c|}{ R-squared $=0.9822$} \\
\hline & & & \multicolumn{3}{|c|}{ Adj R-squared $=0.9746$} \\
\hline & Partial & & & & Prob > \\
\hline Source & SS & df & MS & $\mathrm{F}$ & $\mathrm{F}$ \\
\hline Model & 12.3599 & 64 & 0.1931 & 128.47 & 0 \\
\hline \multirow[t]{2}{*}{ Pt.ID } & 0.2582 & 55 & 0.0047 & 3.12 & 0 \\
\hline & & & & 2648.8 & \\
\hline Age & 11.9463 & 3 & 3.9821 & 9 & 0 \\
\hline Skeletal.Q & 0 & 0 & & & \\
\hline \multicolumn{6}{|l|}{ Age \# } \\
\hline Skeletal.Q & 0.0086 & 6 & 0.0014 & 0.96 & 0.4578 \\
\hline Residual & 0.2240 & 149 & 0.0015 & & \\
\hline Total & 12.5839 & 213 & 0.0591 & & \\
\hline Between-s & $\begin{array}{l}\text { ects error } \\
\text { term: }\end{array}$ & \multicolumn{4}{|c|}{ Age \# Skeletal.Q } \\
\hline & Levels: & \multicolumn{4}{|c|}{12 (6df) } \\
\hline \multirow{2}{*}{\multicolumn{2}{|c|}{$\begin{array}{r}\text { Lowest b.s.e. variable: } \\
\text { Covariance pooled } \\
\text { over: }\end{array}$}} & \multicolumn{4}{|l|}{ Age } \\
\hline & & \multicolumn{4}{|c|}{ Skeletal.Q (for repeated variable) } \\
\hline \multicolumn{2}{|c|}{ Repeated variable: } & \multicolumn{4}{|c|}{ Pt.ID } \\
\hline
\end{tabular}

\begin{tabular}{|c|c|c|c|c|}
\hline \multicolumn{5}{|c|}{ (b) Tukey's HSD } \\
\hline \multicolumn{5}{|c|}{$\begin{array}{l}\text { studentized range critical value }(.05,3,149)=3.3480 \\
\text { uses harmonic mean sample size }=71.292 \\
\text { quantile vs }\end{array}$} \\
\hline $\begin{array}{l}\text { delayed vs } \\
\text { average }\end{array}$ & 0.6064 & 0.6030 & 0.0034 & 0.7330 \\
\hline $\begin{array}{l}\text { delayed vs } \\
\text { advanced } \\
\text { average vs } \\
\text { advanced }\end{array}$ & 0.6064 & 0.6319 & 0.0255 & $5.5630^{*}$ \\
\hline
\end{tabular}

Results for Quantiles Based on Dental Development The descriptive statistics of the dental based quantiles (see Table 4c) demonstrate that, for the delayed and average quantiles, dental development is consistently less varied than skeletal development (see Table 5c), as is predicted. However, the advanced quantile varies by age in terms of which systems' development has greater variation. At ages three and nine the skeletal development is more varied, while ages six and 12 have greater variation in the dental development.
Model 1: Dental Developmental Trajectories of Dental Quantiles

In Figure 2a, the dental developmental trajectories of the three dental quantiles versus the exact age is shown. Model 3 is similar to Model 1 in that the system's development being measured (dental for Model 3, skeletal for Model 1) is the same as the system upon which the quantiles were defined. From age three to age 12, the difference in dental development between the delayed-dental quantile and the advanced-dental quantile decreases. However, the decrease does not occur continuously, as it does for Model 1. The dental development of the three dental quantiles was compared by a repeated measure ANOVA (Table 8a). As was the case with Models 1 and 2, Model 3 was significant $(\mathrm{F}=154.32$; $\mathrm{p}<0.0001)$. Corresponding to the observed significance of Model 1, in Model 3 age was significant, as was the interaction of age and dental quantile. The R-squared was 0.9848 . As Model 3 was significant, Tukey's HSD was again run. The results of the Tukey's HSD demonstrated that all three pairwise comparisons between the dental quantiles were significant (Table 8b). This consistent significance of the pairwise comparisons is similar to Model 1, in which the skeletal development was compared between the skeletal quantiles.

\section{Model 2: Skeletal Developmental Trajectories of Dental} Quantiles

Figure $2 \mathrm{~b}$ depicts the skeletal developmental trajectories of those individuals whose dental development was delayed, average, or advanced at age three. This mixed combination of systems is similar to Model 2, although Model 4 includes the same individuals as Model 3. The repeated measure ANOVA of Model 4 (Table 9a) found that the model was again significant $(\mathrm{F}=98.95 ; \mathrm{p}<0.0001)$. The pattern of significance for Model 4 matches that of Model 2. Age was significant, while the interaction between age and dental quantile was not $(\mathrm{p}=0.39665)$. Of the four models, Model 4 has the lowest R-squared (0.9769), although the R-squared value is still quite high. Tukey's HSD was required as the model was significant (Table 9b). Of the pairwise comparisons in Model 4, only that between the average and advanced quantiles was significant. The delayed quantile mean was not significantly different than either the average or advanced quantiles.

\section{Discussion}

The null hypothesis, that the developmental trajectories do not vary between delayed, average, and advanced individuals, failed to be rejected univer- 
Table 8. Model 3: Dental development between dental quantiles. Pt.ID: individual; Age: patient's chronological age; Dental.Q: patient's dental quantile.

\begin{tabular}{|c|c|c|c|c|c|}
\hline \multicolumn{6}{|c|}{ (a) Repeat Measure ANOVA } \\
\hline \multirow{2}{*}{\multicolumn{3}{|c|}{$\begin{array}{l}\text { Number of observations }=211 \\
\text { Root MSE }=0.0361\end{array}$}} & \multicolumn{3}{|c|}{ R-squared $=0.9848$} \\
\hline & & & \multicolumn{3}{|c|}{ Adj R-squared $=0.9784$} \\
\hline & Partial & & & & Prob \\
\hline Source & SS & $\mathrm{df}$ & MS & $\mathrm{F}$ & $>\mathrm{F}$ \\
\hline Model & 12.4365 & 62 & 0.2006 & 154.32 & 0 \\
\hline Pt.ID & 0.2711 & 53 & 0.0051 & 3.94 & 0 \\
\hline Age & 12.0967 & 3 & 4.0322 & 3102.22 & 0 \\
\hline $\begin{array}{l}\text { Dental.Q } \\
\text { Age \# }\end{array}$ & 0 & 0 & & & \\
\hline Dental.Q & 0.0363 & 6 & 0.0060 & 4.65 & 0.0002 \\
\hline Residual & 0.1924 & 148 & 0.0013 & & \\
\hline Total & 12.6289 & 210 & 0.0601 & & \\
\hline \multicolumn{6}{|c|}{$\begin{array}{r}\text { Between-subjects } \\
\text { error term: }\end{array}$} \\
\hline \multirow{2}{*}{\multicolumn{2}{|c|}{$\begin{array}{r}\text { Levels: } \\
\text { Lowest b.s.e. variable: } \\
\text { Covariance pooled } \\
\text { over: }\end{array}$}} & \multicolumn{4}{|c|}{12 (6df) } \\
\hline & & \multicolumn{3}{|l|}{ Age } & able) \\
\hline \multicolumn{2}{|c|}{ Repeated variable: } & \multicolumn{4}{|c|}{ Pt.ID } \\
\hline
\end{tabular}

\begin{tabular}{|c|c|c|c|c|}
\hline \multicolumn{5}{|c|}{ (b) Tukey's HSD } \\
\hline \multicolumn{5}{|c|}{ studentized range critical value $(.05,3,148)=3.3483$} \\
\hline \multicolumn{5}{|c|}{ uses harmonic mean sample size $=70.33$} \\
\hline quantile vs & & & mean & \\
\hline quantile & quanti & means & dif & HSD-test \\
\hline $\begin{array}{l}\text { average } \\
\text { delayed vs }\end{array}$ & 0.5846 & 0.6146 & 0.0299 & $6.9620^{*}$ \\
\hline $\begin{array}{l}\text { advanced } \\
\text { average vs }\end{array}$ & 0.5846 & 0.6327 & 0.0480 & $11.1732 *$ \\
\hline advanced & 0.6146 & 0.6327 & 0.0181 & $4.2112^{*}$ \\
\hline
\end{tabular}

sally. When the quantiles were defined based on the skeletal system, the skeletal developmental trajectories clearly differ between the delayed, average, and advanced quantiles. This is evident in the continuously decreasing differences between the delayed and advanced quantiles, as depicted in Figure 1a. The significance of the interaction terms in Model 1 indicates that the trajectories are different; they are not parallel versions simply offset from each other. This means that the rates of skeletal development differ, as do the absolute agespecific developmental percentages quantiles. The null hypothesis was, therefore, rejected based on the significance of the Tukey HSD test of Model 1.

However, when the dental development of these same individuals was considered in Model 2, the three quantiles did not follow significantly dif-
Table 9. Model 4: Skeletal development between dental quantile. Pt.ID: individual; Age: patient's chronological age; Dental.Q: patient's dental quantile.

\begin{tabular}{|c|c|c|c|c|c|}
\hline \multicolumn{6}{|c|}{ (a) Repeat Measure ANOVA } \\
\hline \multirow{2}{*}{\multicolumn{3}{|c|}{$\begin{array}{l}\text { Number of observations }=208 \\
\text { Root MSE }=0.0399\end{array}$}} & \multicolumn{3}{|c|}{ R-squared $=0.9769$} \\
\hline & & & \multicolumn{3}{|c|}{ Adj R-squared $=0.9670$} \\
\hline & Partial & & & & Prob > \\
\hline Source & SS & df & MS & F & $\mathrm{F}$ \\
\hline Model & 9.7891 & 62 & 0.1579 & 98.95 & 0 \\
\hline Pt.ID & 0.6146 & 53 & 0.0116 & 7.27 & 0 \\
\hline Age & 8.9928 & 3 & 2.9976 & 1878.65 & 0 \\
\hline $\begin{array}{l}\text { Dental.Q } \\
\text { Age \# }\end{array}$ & 0 & 0 & & & \\
\hline Dental.Q & 0.0100 & 6 & 0.0017 & 1.05 & 0.3965 \\
\hline Residual & 0.2314 & 145 & 0.0016 & & \\
\hline Total & 10.0205 & 207 & 0.0484 & & \\
\hline \multicolumn{6}{|c|}{$\begin{array}{r}\text { Between-subjects } \\
\text { error term: }\end{array}$} \\
\hline \multirow{2}{*}{\multicolumn{2}{|c|}{$\begin{array}{r}\text { Levels: } \\
\text { Lowest b.s.e. variable: } \\
\text { Covariance pooled } \\
\text { over: }\end{array}$}} & \multicolumn{4}{|c|}{$12(6 \mathrm{df})$} \\
\hline & & \multicolumn{4}{|l|}{ Age } \\
\hline \multicolumn{2}{|c|}{ Repeated variable: } & Pt.ID & & & \\
\hline
\end{tabular}

\section{(b) Tukey's HSD}

studentized range critical value $(.05,3,145)=3.3490$

uses harmonic mean sample size $=69.33$

\begin{tabular}{lcccc}
$\begin{array}{l}\text { quantile vs } \\
\text { quantile } \\
\text { delayed vs } \\
\begin{array}{l}\text { average } \\
\text { delayed vs }\end{array}\end{array}$ & quantile means & $\begin{array}{c}\text { mean } \\
\text { dif }\end{array}$ & HSD-test \\
$\begin{array}{l}\text { advanced } \\
\begin{array}{l}\text { average vs } \\
\text { advanced }\end{array}\end{array}$ & 0.6175 & 0.6056 & 0.0119 & 2.4799 \\
\hline
\end{tabular}

ferent developmental trajectories; only the advanced quantile was significantly different from the other two. The non-significance of the interaction term from Model 2's repeated measure ANOVA indicates that the trajectories are parallel. Therefore, while the rate of dental development is similar for the three quantiles, those who were skeletally advanced begin and remain relatively advanced dentally.

This difference in significance is unexpected. Growth charts, such as those released by the World Health Organization (WHO) and Center for Disease Control (CDC), show that percentiles diverge as individuals age (WHO Multicenter Growth Reference Study Group, 2006). The Greulich \& Pyle logarithmic development graphs are suggestive of different developmental trajectories (Greulich \& 
(a) Model 3: dental development of dental quantiles

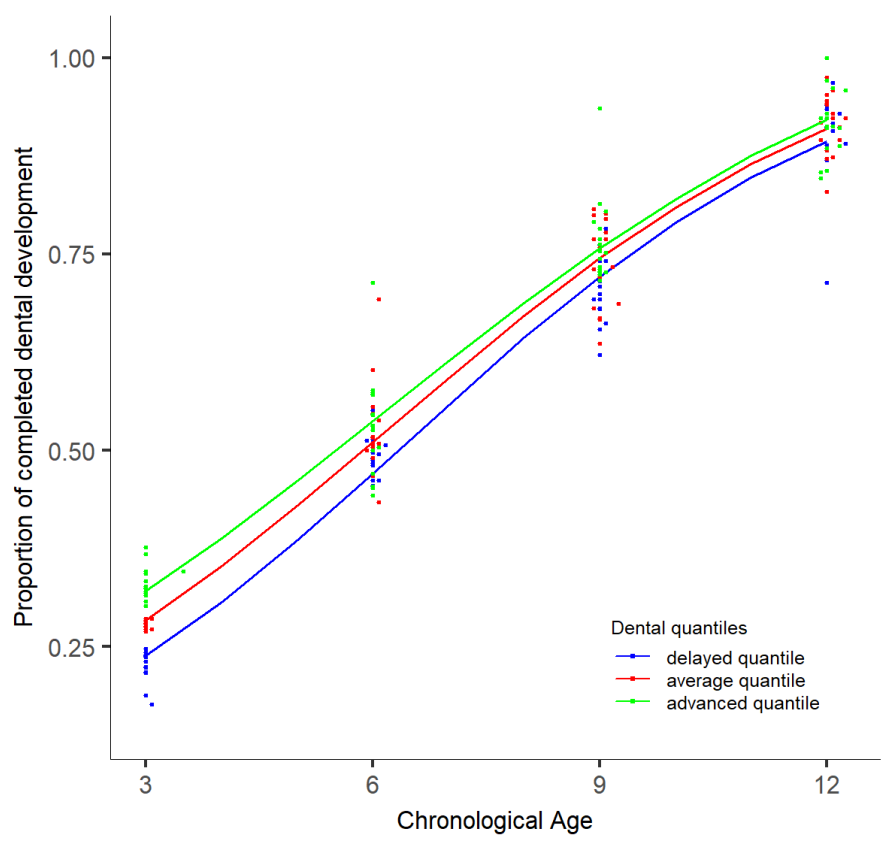

(b) Model 4: skeletal development of dental quantiles

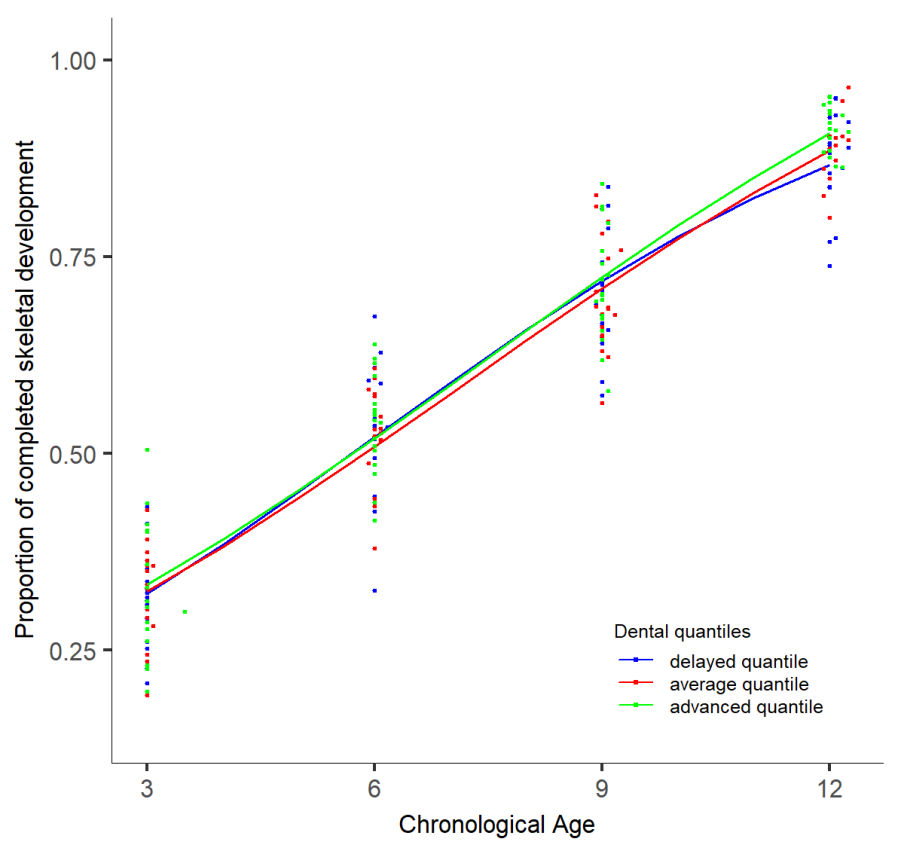

Figure 2. Logistic growth curves of dental quantiles: chronological age versus development. Plots of chronological age by proportion of completed dental (a) or skeletal (b) development based on dental development at age three, the delayed, average, and advanced dental quantiles. Logistic growth curves depict the developmental trajectories taken by those within each quantile.

Pyle, 1959), which also influenced the hypothesized difference between quantiles. If the two systems are correlated, and the body's approach to the development of both systems is the same, then it would be expected that the developmental trajectories of the dental system would also be significantly different, given the skeletal system's trajectories. That the dental system in general varies less than the skeletal system does not seem to be sufficient explanation for why the advanced quantile followed significantly different developmental trajectories than the delayed and average quantiles.

From the analysis of dental quantiles, the null hypothesis again was rejected as the dental developmental trajectories (Tukey HSD test of Model 3) were all significantly different and not parallel. As with Model 1, this finding is consistent with existing maturation charts such as those by Moorrees et al. (1963). It is interesting and noteworthy that while the dental developmental trajectories of the dental quantiles (Model 3) are all significantly different from one another, the delayed and average skeletal quantiles (Model 2) do not follow significantly different dental developmental trajectories.

Differences in skeletal development among the dental quantiles also reject the null hypothesis, although only the average and advanced dental quantiles followed significantly different skeletal developmental trajectories from each other. As the interaction term from Model 4 was not significant, it is apparent that these two quantiles followed different, yet parallel, trajectories. As depicted in Figure $2 b$, the difference between the average and advanced quantiles, while significant, is not great. Given this small difference, the variation of the delayed quantile shows an erratic pattern between the other two quantiles without being significantly different from either.

While the advanced subgroup is the only one that was consistently different throughout the analyses, these four models demonstrate that the relative relationship between the skeletal and dental systems are not the same throughout the range of IVDT.

This study did not take into consideration possible stressors that might influence the skeletal or dental development. It is possible that future research that considers such stressors will offer insight into possible tradeoffs occurring between the systems that might explain these unexpected results from skeletal based quantiles.

\section{Conclusions}

This research has demonstrated the importance of considering the possibility that those individuals towards the extremes of normal IVDT may follow different developmental trajectories than is fully characterized by the sample mean. We have shown 
that for skeletal and dental development, the trajectories are significantly different between those who are delayed, average, and advanced early in life. That this significance varies, and that the trajectories are occasionally parallel when the opposite system is considered, suggests that the relationship between the development of the skeletal and dental systems is more complicated than has been previously explored.

It is important to note that while the skeletal and dental quantiles were assigned independently, there are 32 individuals who fall into the quantiles of interest for both systems (see Table 3c). Of these individuals, less than a third were classified in the same level of quantile for both systems ( 5 delayed, 1 average, 4 advanced). Slightly over a quarter of the individuals who were delayed in one system were advanced in the other (3 delayed skeletal, 5 delayed dental). Based on the plethora of research finding a positive, and often significant, correlation between the systems, this discrepancy of a quarter of the individuals is surprising and warrants further investigation.

The variation between the systems' developmental trajectories has been shown to vary between individuals who were delayed, average, or advanced in their development at an early age, and additional research is needed to further explore the full range of IVDT.

\section{Acknowledgments}

The authors would like to thank the Bolton-Brush Growth Study for access to their collection. This research was funded by the University of New Mexico's Evolutionary Anthropology's Research Development Grant, and the Office of Graduate Studies Research, Project, and Travel Grant.

The authors declare no potential conflicts of interest with respect to the authorship and/or publication of this article.

\section{REFERENCES}

Al-Juboori, H. A., Saloom, H. F., \& Al-Bustani, A. (2012). Estimation of pubertal growth using Hand-Wrist radiographs and Orthopantomographs (prospective study). Mustansiria Dental Journal, 9(1), 22-31.

AlQahtani, S., Hector, M., \& Liversidge, H. (2010). Brief communication: The London atlas of human tooth development and eruption. American Journal of Physical Anthropology, 142(3), 481490.

Anderson, D. L., Thompson, G. W., \& Popovich, F. (1975). Interrelationships of dental maturity, skeletal maturity, height and weight from 4 to 14 years. Growth, 39, 453-462.

Arora, V. (2009). Assessment of Dental and Skeletal Age by Radiographic Method in Subjects Between 9 -16 Years (Doctoral Dissertation). K.L.E. University, Belgaum, Karnataka.

Badyaev, A. V. (2002). Growing apart: An ontogenetic perspective on the evolution of sexual size dimorphism. Trends in Ecology \& Evolution, 17(8), 369-378.

Bagherpour, A., Pousti, M., \& Adelianfar, E. (2014). Hand skeletal maturity and its correlation with mandibular dental development. Journal of Clinical and Experimental Dentistry, 6(3), e275e279.

Behrents, R. G. (1984). In search of truth for the greater good of man: A chronological account of the Bolton-Brush growth studies. Case Western Reserve University.

Boas, F. (1912). Changes in the bodily form of descendants of immigrants. American Anthropologist, 14(3), 530-562.

Bogin, B. (1997). Evolutionary hypotheses for human childhood. Yearbook of Physical Anthropolo$g y, 40,63-89$.

Cardoso, H. F. V. (2007a). Differential sensitivity in growth and development of dental and skeletal tissue to environmental quality. ArquiMed, 21 (1), 19-23.

Cardoso, H. F. V. (2007b). Environmental effects on skeletal versus dental development: Using a documented subadult skeletal sample to test a basic assumption in human osteological research. American Journal of Physical Anthropolo$g y, 132(2), 223-233$.

Cardoso, H. F. V., Heuze, Y., \& Julio, P. (2010). Secular change in the timing of dental root maturation in Portuguese boys and birls. American Journal of Human Biology, 22(6), 791-800.

Demirjian, A., Buschang, P. H., Tanguay, R., \& Kingnorth Patterson, D. (1985). Interrelationships among measures of somatic, skeletal, dental, and sexual maturity. American Journal of Orthodontics, 88(5), 433-438.

Flatt, T. (2005). The evolutionary genetics of canalization. The Quarterly Review of Biology, 80(3), 287-316.

Flores-Mir, C., Mauicio, F. R., Orellena, M. F., \& Major, P. W. (2005). Association between growth stunting with dental development and skeletal maturation stage. Angle Orthodontist, 75(6), 935-940.

Fox, J., \& Weisberg, S. (2010). Nonlinear regression and nonlinear least squares in R. In An Appen- 
dix to An R Companion to Applied Regression (Second). Retrieved from http:// www.stat.wvu.edu/ jharner/courses/ stat512/docs/Nonlinear-Regression.pdf

Garn, S. M. (1987). The secular trend in size and maturation timing and its implications for nutritional assessment. The Journal of Nutrition, 117(5), 817-823.

Greulich, W. W., \& Pyle, S. I. (1959). Radiographic atlas of skeletal development of the hand and wrist (2nd Edition). Stanford, Calif: Stanford University Press.

Gupta, M., Divyashree, R., Abhilash, P. R., Bijle, M. N. A., \& Murali, K. V. (2013). Correlation between chronological age, dental age and skeletal age among monozygotic and dizygotic twins. Journal of International Oral Health, 5(1), 16-22.

Haiter-Neto, F., Kurita, L. M., Menezes, A. V., \& Casanova, M. S. (2006). Skeletal age assessment: A comparison of 3 methods. American Journal of Orthodontics and Dentofacial Orthopedics, 130(4), 435.e15-435.e20.

Hans, M. G., Broadbent Jr., B. H., \& Nelson, S. S. (1994). The Broadbent-Bolton Growth study past, present, and future. American Journal of Orthodontics and Dentofacial Orthopedics, 105(6), 598-603.

Hochberg, Z., Feil, R., Constancia, M., Fraga, M., Junien, C., Carel, J.-C., ... Albertsson-Wikland, K. (2011). Child health, developmental plasticity, and epigenetic programming. Endocrine Reviews, 32(2), 159-224.

Houston, A. I., \& McNamara, J. M. (1992). Phenotypic plasticity as a state-dependent life-history decision. Evolutionary Ecology, 6(3), 243-253.

Humphrey, L. T. (1998). Growth patterns in the modern human skeleton. American Journal of Physical Anthropology, 105(1), 57-72.

Hunt, E. E. Jr., \& Gleiser, I. (1955). The estimation of age and sex of preadolescent children from bones and teeth. American Journal of Physical Anthropology, 13(3), 479-487.

Jasienska, G. (2013). The fragile wisdom: An evolutionary view on women's biology and health. Cambridge, Massachusetts: Harvard University Press.

Kuzawa, C. W. (2012). Why evolution needs development, and medicine needs evolution. International Journal of Epidemiology, 41(1), 223-339.

Landis, J. R., \& Koch, G. G. (1977). The measurement of observer agreement for categorical data. Biometrics, 33(1), 159-174.

Lauterstein, A. M. (1961). A cross-sectional study in dental development and skeletal age. Journal of the American Dental Association, 62(2), 161167.

Lewis, A. B., \& Garn, S. M. (1960). The relationship between tooth formation and other maturational factors. The Angle Orthodontist, 30(2), 7077.

Love, A. C. (Ed.). (2014). Conceptual change in biology: Scientific and philosophical perspectives on evolution and development. New York: Springer.

Moorrees, C. F. A., Fanning, E. A., \& Hunt, E.E. Jr. (1963). Age variation of formation stages for ten permanent teeth. Journal of Dental Research, 42(6), 1490-1502.

Nadler, G. L. (1998). Earlier dental maturation: Fact or fiction? The Angle Orthodontist, 68(6), 535538.

Nelson, S., Hans, M. G., Broadbent Jr., B. H., \& Dean, D. (2000). The brush inquiry: An opportunity to investigate health outcomes in a wellcharacterized cohort. American Journal of $\mathrm{Hu}$ man Biology, 12(1), 1-9.

Ogden, C. L., Kuczmarski, R. J., Flegal, K. M., Mei, Z., Guo, S., Wei, R., ... Johnson, C. L. (2002). Centers for disease control and prevention 2000 growth charts for the United States: Improvements to the 1977 National Center for Health Statistics version. Pediatrics, 109(1), 4560.

Rautman, A. L. M., \& Edgar, H. J. H. (2013). Secular change in dental development in New Mexican females. Dental Anthropology, 26(3), 31-37.

Ribot, I., \& Roberts, C. (1996). A study of nonspecific stress indicators and skeletal growth in two mediaeval subadult populations. Journal of Archaeological Science, 23, 67-79.

Sachan, K., Sharma, V., \& Tandon, P. (2011). A correlative study of dental age and skeletal maturation. Indian Journal of Dental Research, 22(6), 882.

Saglam, A. M. S., \& Gazilerli, Ü. (2002). The relationship between dental and skeletal maturity. Journal of Orofacial Orthopedics, 63, 454-462.

Stinson, S. (1985). Sex differences in environmental sensitivity during growth and development. Yearbook of Physical Anthropology, 28, 123-147.

Tanner, J. M. (1978). Fetus into man: Physical growth from conception to maturity. Cambridge, Massachusetts: Harvard University Press.

Viera, A. J., \& Garrett, J. M. (2005). Understanding interobserver agreement: The Kappa statistic. Family Medicine, 37(5), 360-363.

Waddington, C. H. (1942). Canalization of development and the inheritance of acquired charac- 
ters. Nature, 150(3811), 563-565.

Wang, Z., Pang, X., Wu, W., Wang, J., Wang, Z., \& Wu, R. (2014). Modeling phenotypic plasticity in growth trajectories: A statistical framework. Evolution, 68(1), 81-91.

WHO Multicenter Growth Reference Study Group. (2006). WHO Child growth standards: Length/ height-for-age, weight-for-age, weight-for-length, weight-for-height and body mass index-for-age: Methods and development. (p. 312) [Technical]. Retrieved from World Health Organization website: http:/ / www.who.int/childgrowth/ standards/technical_report/en/

Zhang, A., Sayre, J. W., Vachon, L., Liu, B. J., \& Huang, H. K. (2009). Racial differences in growth patterns of children assessed on the basis of bone age. Radiology, 250(1), 228-235. 